\title{
Most Vesicles in a Central Nerve Terminal Participate in Recycling
}

\author{
Lei Xue, ${ }^{1,2 \star}$ Jiansong Sheng, ${ }^{1 \star}$ Xin-Sheng Wu, ${ }^{1}$ Wei Wu, ${ }^{1}$ Fujun Luo, ${ }^{1}$ Wonchul Shin, ${ }^{1}$ Hsueh-Cheng Chiang, ${ }^{1}$ \\ and Ling-Gang $\mathrm{Wu}^{1}$ \\ ${ }^{1}$ Synaptic Transmission Section, National Institute of Neurological Disorders and Stroke, Bethesda, Maryland 20892, and 2Department of Physiology and \\ Biophysics, Fudan University, Shanghai 200433, China
}

Studies over the last decade using FM dyes to label vesicles at many terminals, including the calyx-type nerve terminal, led to a well accepted "principle" that only a small fraction of vesicles $(\sim 5-20 \%)$ participate in recycling under physiological conditions. This principle imposes a large challenge in maintaining synaptic transmission during repetitive firing, because the small recycling pool may limit the number of available vesicles for release and nerve terminals would have to distinguish the recycling pool from the reserve pool and keep reserve pool vesicles from being used. By recording the presynaptic capacitance changes and the postsynaptic EPSC at rat calyx of Held synapses in the absence or presence of transmitter glutamate in nerve terminals, we developed a new method to count functional recycling vesicles. We found that essentially all vesicles in calyces participated in recycling, challenging the small-recycling-pool principle established by FM dye labeling. Nerve terminals may use all available vesicles to maximize their ability in maintaining synaptic transmission during repetitive firing.

\section{Introduction}

Maintaining synaptic transmission relies on vesicle recycling. FM dye labeling in the last decade suggests that only 5-20\% vesicles participate in recycling during firing at $\leq 30 \mathrm{~Hz}$ at many synapses, including neuromuscular junctions, hippocampal synapses, and calyx-type synapses (Harata et al., 2001b; de Lange et al., 2003; Richards et al., 2003; Denker et al., 2011). This well accepted small-recycling-pool principle (Rizzoli and Betz, 2005) imposes large challenges for neurons to maintain synaptic transmission during repetitive firing. It raises the question as to why most vesicles do not participate in recycling and how recycling vesicles are distinguished from non-recycling vesicles.

Here we developed a technique to count recycling vesicles at the calyx of Held nerve terminal, where FM dye labeling showed morphologically a small recycling pool ( 5\%) (de Lange et al., 2003). By preventing glutamate uptake into recycled vesicles, we found an activity-dependent reduction of the EPSC reflecting recycling of vesicles containing no glutamate. The sum of the EPSC, which reflected the functional recycling pool size, was as large as the entire vesicle pool, challenging the small-recyclingpool "principle."

Received Aug. 20, 2012; revised April 8, 2013; accepted April 12, 2013.

Author contributions: L.X., J.S., and L.-G.W. designed research; L.X., J.S., X.-S.W., W.W., and F.L. performed research; L.X., J.S., X.-S.W., W.W., W.S., and H.-C.C. analyzed data; L.-G.W. wrote the paper.

This work was supported by the National Institute of Neurological Disorders and Stroke Intramural Research Program.

*L.X. and J.S. contributed equally to this work.

Correspondence should be addressed to either Ling-Gang Wu or Lei Xue, Synaptic Transmission Section, National Institute of Neurological Disorders and Stroke, 35 Convent Drive, Building 35, Room 2B-1012, Bethesda, MD 20892, E-mail: Ixue@fudan.edu.cn orwul@ninds.nih.gov.

DOI:10.1523/JNEUROSCI.4029-12.2013

Copyright $\odot 2013$ the authors $\quad 0270-6474 / 13 / 338820-07 \$ 15.00 / 0$

\section{Materials and Methods}

Preparation of brainstem slices containing calyces of Held from Wistar rats of either sex (7-10 d old), whole-cell measurements of presynaptic calcium currents and capacitance (EPC-10 amplifier), and the EPSCs and mEPSCs (Axopatch $200 \mathrm{~B}$ amplifier) at room temperature $\left(22-24^{\circ} \mathrm{C}\right.$ ) have been described previously (Wu et al., 2009). The holding potential for presynaptic and postsynaptic recordings was $-80 \mathrm{mV}$. Data were expressed as the mean \pm SEM. The statistical test used was the $t$ test.

The presynaptic pipette $(2.5-4.5 \mathrm{M} \Omega$ ) solution contained the following (in mM): 125 Cs-gluconate, $20 \mathrm{CsCl}, 4 \mathrm{MgATP}, 10 \mathrm{Na}_{2}$-phosphocreatine, 0.3 GTP, 10 HEPES, and 0.05 BAPTA, pH 7.2 adjusted with CsOH. When glutamate (potassium L-glutamate, $10 \mathrm{~mm}$ ) was added, Cs-gluconate was reduced to maintain the same osmolarity (310-325 mOsm). The bath solution contained the following (in $\mathrm{mM}$ ): $105 \mathrm{NaCl}, 20 \mathrm{TEA}-\mathrm{Cl}, 2.5 \mathrm{KCl}$, $1 \mathrm{MgCl}_{2}, 2 \mathrm{CaCl}_{2}, 25 \mathrm{NaHCO}_{3}, 1.25 \mathrm{NaH}_{2} \mathrm{PO}_{4}, 25$ dextrose, 0.4 ascorbic acid, 3 myo-inositol, 2 sodium pyruvate, 0.001 tetrodotoxin, $0.13,4$ diaminopyridine, 0.05 D-APV, $\mathrm{pH} 7.4$ when bubbled with $95 \% \mathrm{O}_{2}$ and $5 \%$ $\mathrm{CO}_{2}$. The postsynaptic pipette (2-3 M $\Omega$ ) solution contained the following (in $\mathrm{mM}$ ): $125 \mathrm{~K}$-gluconate, $20 \mathrm{KCl}, 4 \mathrm{MgATP}, 10 \mathrm{Na}_{2}$-phosphocreatine, 0.3 GTP, 10 HEPES, and 0.5 EGTA, pH 7.2, adjusted with $\mathrm{KOH}$. The series resistance $(<12 \mathrm{M} \Omega$ ) was compensated by $90 \%$ (lag $10 \mu \mathrm{s}$ ).

Fura-2 fluorescence imaging was performed on an upright epifluorescence microscope (Olympus BX51WI, Achroplan 40×, numerical aperture 0.75 , Zeiss) equipped with a monochromator (TILL Photonics), a dichroic mirror (400 nm), an emission filter (510 nm long pass), and a CCD camera (EM CCD 9100, Hamamatsu Photonics). Images were analyzed using the software Openlab 5.5 (Improvision).

\section{Results}

Activity-dependent EPSC decrease in the absence of glutamate

The calyx and the postsynaptic neuron were voltage-clamped. Kynurenic acid (1 mM, bath) was included to relieve AMPA receptor saturation (Sun and Wu, 2001; Scheuss et al., 2002; Wong et al., 2003). At 1-2 min after whole-cell break-in, the calyx was 

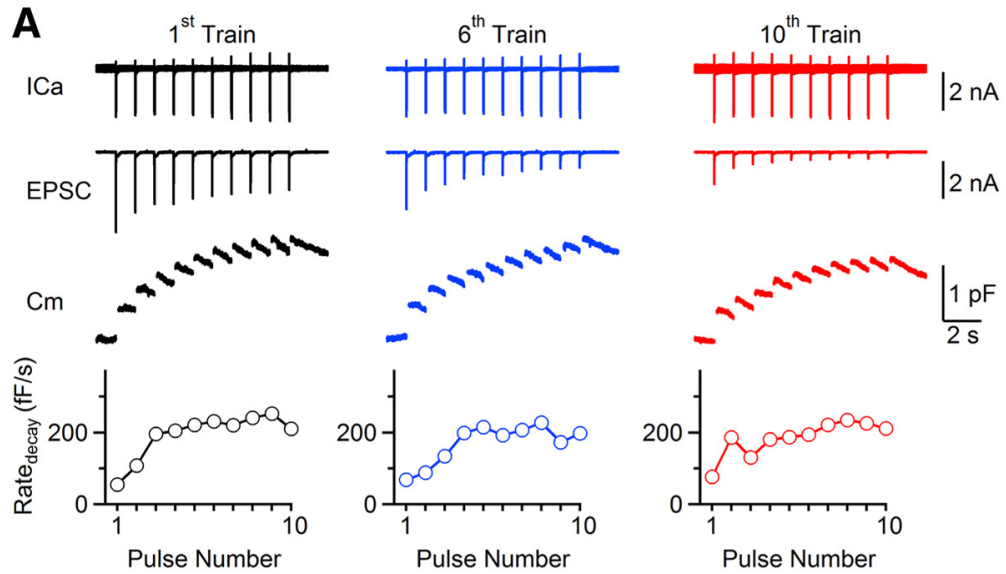

B
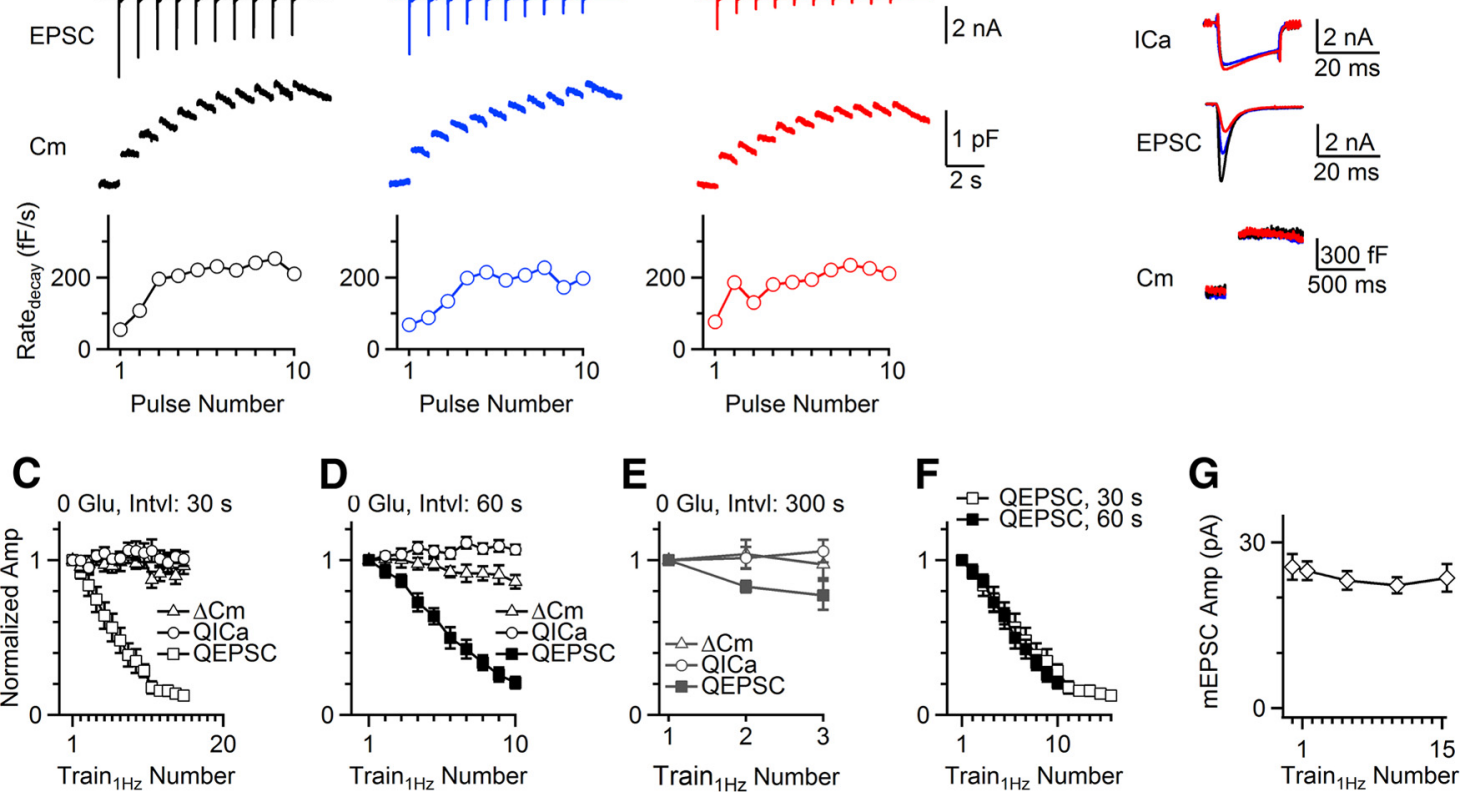

Figure 1. Activity-dependent EPSC decrease in the absence of glutamate. $A$, Sampled presynaptic calcium currents (ICa), EPSCs, and presynaptic $C_{\mathrm{m}}$ induced by the first, sixth, and 10 th Train $_{1 \mathrm{~Hz}}$ applied every $30 \mathrm{~s}$. The rate of $C_{\mathrm{m}}$ decay (Rate ${ }_{\text {decay }}$ ) in the interval between each $20 \mathrm{~ms}$ depolarization during $\operatorname{Train}_{{ }_{1 \mathrm{~Hz}}}$ is also plotted. The presynaptic pipette contained $0 \mathrm{~mm}$ glutamate ( $G$ lu applies to $A-G) . B, I C a, E P S C$, and $C_{m}$ induced by the first $20 \mathrm{~ms}$ depolarization during first (black), sixth (blue), and 10th (red) Train ${ }_{1 H z}$ shown in $A$ are superimposed. $C-E$, The QICa, $\Delta C_{m}$, and QEPSC induced by each $\operatorname{Train}_{1 \mathrm{~Hz}}$ are plotted versus the number of $\operatorname{Train}_{1 \mathrm{~Hz}}$ applied every $30 \mathrm{~s}(\boldsymbol{C}, n=8), 60 \mathrm{~s}(\boldsymbol{D}, n=8)$, or $300 \mathrm{~s}(\boldsymbol{E}, n=5)$. Data were normalized to the amplitude (Amp) induced by the first $\operatorname{Train}_{1 \mathrm{~Hz}}$ and expressed as the mean \pm SEM (applied to all figures). $F$, QEPSC in $\boldsymbol{C}$ and $\boldsymbol{D}$ are plotted versus the Train ${ }_{1 \mathrm{~Hz}}$ number. $\mathbf{G}$, The mean $\mathrm{mEPSC}$ amplitude recorded between Train ${ }_{1 \mathrm{~Hz}} \mathrm{applied} \mathrm{every} 30 \mathrm{~s}$ for 15 times ( $n=4$ synapses, no kynurenic acid in bath).

stimulated with 10 pulses of $20 \mathrm{~ms}$ depolarization (from -80 to $+10 \mathrm{mV})$ at $1 \mathrm{~Hz}\left(\operatorname{Train}_{1 \mathrm{~Hz}}\right)$. Train ${ }_{1 \mathrm{~Hz}}$ induced a presynaptic calcium current charge (QICa) of $366 \pm 42 \mathrm{pC}$, a membrane capacitance jump $\left(\Delta C_{\mathrm{m}}\right)$ of $2898 \pm 276 \mathrm{fF}$ (the sum of $\Delta C_{\mathrm{m}}$ induced by each $20 \mathrm{~ms}$ depolarization, not the net increase) and an EPSC charge (QEPSC) of $94 \pm 11 \mathrm{pC}(n=8$, Fig. $1 A, B)$.

As Train ${ }_{1 \mathrm{~Hz}}$ was repeated every $30 \mathrm{~s}(n=8$, Fig. $1 C), 60 \mathrm{~s}(n=$ 8 , Fig. $1 D)$, or $300 \mathrm{~s}(n=5$, Fig. $1 E), \Delta C_{\mathrm{m}}$ and QICa induced by Train $_{1 \mathrm{~Hz}}$ did not decrease significantly, whereas QEPSC decreased to near 0 at $\geq 10$ th $^{\text {Train }} 1 \mathrm{~Hz}$. QEPSC decrease was fastest at $30 \mathrm{~s}$ interval, slower at $60 \mathrm{~s}$ interval, and very slowly at $300 \mathrm{~s}$ interval (Fig. 1C-E). Plotting QEPSC versus the number of Train $_{1 \mathrm{~Hz}}$ applied every 30 or $60 \mathrm{~s}$ showed similar decreases at the same Train $_{1 \mathrm{~Hz}}$ number (Fig. $1 F$ ). Thus, the QEPSC decrease is activity dependent. The mEPSC amplitude did not change as Train $_{1 \mathrm{~Hz}}$ was repeated every $30 \mathrm{~s} 15$ times in the absence of glutamate and kynurenic acid (Fig. $1 G ; n=4$ synapses).

The activity-dependent EPSC decrease (Fig. 1) and the persistence of endocytosis in $\sim 10$ min recording (Xu et al., 2008) (Fig. $1 A$ ) suggests that mixing of recycled vesicles lacking glutamate causes the EPSC decrease. The lack of mEPSC amplitude changes (Fig. $1 G$ ) suggests that recycled vesicles contained no glutamate, not a fraction of a normal amount.

\section{Activity-dependent EPSC decrease is due to lack of glutamate refilling}

To confirm that vesicle recycling without glutamate causes the EPSC decrease, we included $10 \mathrm{~mm}$ glutamate in the pipette, at which the mEPSC amplitude does not change (Ishikawa et al., 2002). As Train ${ }_{1 \mathrm{~Hz}}$ was repeated every $60 \mathrm{~s}$ for 10 times, QEPSC,
$\Delta C_{\mathrm{m}}$ and QICa did not decrease significantly (Fig. $2 A-C ; n=3$ ). However, in the presence of bafilomycin A1 ( $6 \mu \mathrm{M}$ in the bath, 20-30 min) that blocks the V-type ATPase-dependent vesicle reacidification and transmitter refilling (Ikeda and Bekkers, 2009), QEPSC, but not $\Delta C_{\mathrm{m}}$ or QICa decreased to $34 \pm 5 \%$ of control ( $n=4$; Fig. $3 A-C$; $p<0.01)$. The QEPSC ( $34 \pm 5 \%)$ was slightly larger than that without glutamate $(21 \pm 4 \%, n=8)$, perhaps due to incomplete block of glutamate refilling. These results strengthen our suggestion that the activity-dependent EPSC decrease is due to recycling of vesicles containing no glutamate.

\section{Negligible glutamate for vesicle uptake}

The following calculations/experiments further support our conclusion that recycled vesicles uptake negligible glutamate. At calyces, glutamate release is complete, because even kiss-and-run fusion takes $\sim 200 \mathrm{~ms}$ with a pore that releases all glutamate within $\sim 5 \mathrm{~ms}$ (He et al., 2006). Since the EPSC decayed to near baseline at $\sim 10-20 \mathrm{~ms}$ during depolarization (Figs. $1 \mathrm{~B}, 2 \mathrm{~B}$ ), and release at the end of $20 \mathrm{~ms}$ depolarization was minimal (Wölfel et al., 2007), the cleft glutamate concentration was negligible after a $20 \mathrm{~ms}$ depolarization. The only time endocytosis might uptake glutamate is the first $10 \mathrm{~ms}$ of a $20 \mathrm{~ms}$ depolarization (Figs. $1 \mathrm{~B}$, $2 \mathrm{~B}$ ), during which endocytosis was negligible because endocytosis is much longer than $10 \mathrm{~ms}$ (Wu et al., 2007). More quantitatively, the capacitance decay rate at the interval between $20 \mathrm{~ms}$ depolarization during Train $_{1 \mathrm{~Hz}}$ reached a similar plateau level $(<260 \mathrm{fF} / \mathrm{s})$ in the absence (Fig. $3 D$, left; $n=8)$ or presence of glutamate (Fig. $3 D$, right; $n=3, p=0.11$ ). Applying this rate $(<260 \mathrm{fF} / \mathrm{s})$ to the first $10 \mathrm{~ms}$ of depolarization for 10 times, we 
A

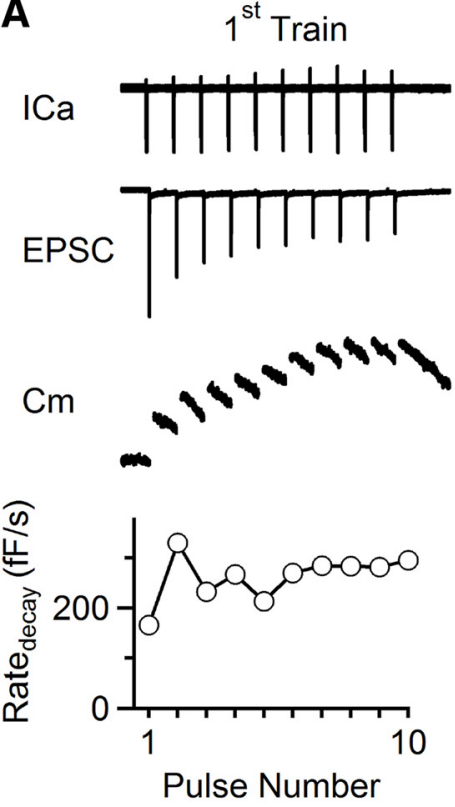

$6^{\text {th }}$ Train
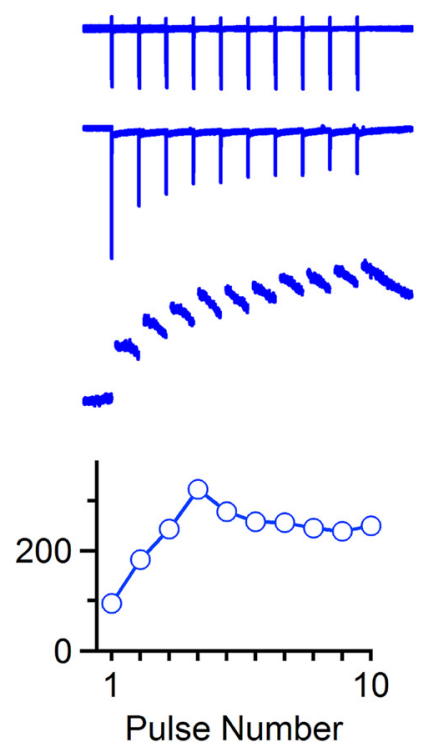

$10^{\text {th }}$ Train
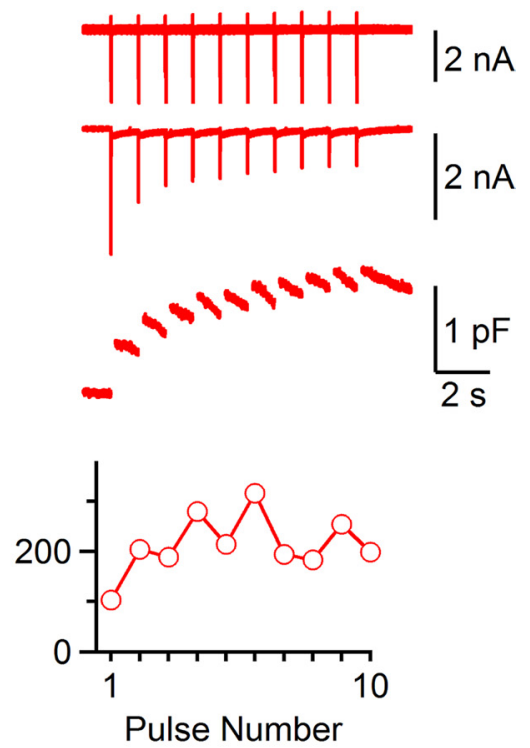

B

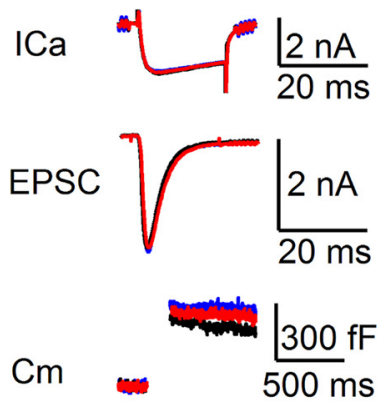

C

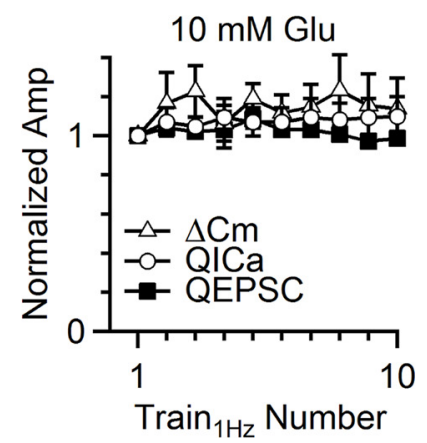

Figure 2. The EPSC does not decrease in the presence of glutamate. $A-C$, Same arrangements as in Figure $1 A, B, D$, respectively, except that the presynaptic pipette contained $10 \mathrm{~mm}$ glutamate

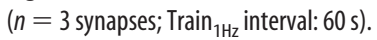

estimated that $<26 \mathrm{fF}(260 \mathrm{fF} / \mathrm{s} \times 0.01 \mathrm{~s} \times 10)$ or $<1 \%(26 / 2898$ $\mathrm{fF})$ of $\Delta C_{\mathrm{m}}(2898 \pm 276 \mathrm{fF}, n=8)$ induced by Train ${ }_{1 \mathrm{~Hz}}$ was retrieved. Thus, glutamate uptake from synaptic clefts was negligible.

Since the pipette solution $(\sim 5 \mu \mathrm{l})$ was much more than the calyx cytosol, cytosolic glutamate should be washed out soon after whole-cell break-in. Indeed, when we loaded calyces with fura-2 by whole-cell break-in with a pipette containing fura-2 $(150 \mu \mathrm{M})$ for $1 \mathrm{~min}$, withdrawal of the pipette, and break-in with another pipette containing no fura-2 decreased fura-2 fluorescence to a near background level within $\sim 20 \mathrm{~s}$ after break-in (Fig. $3 E ; n=4)$. Residual fura-2 fluorescence remained similar afterward (Fig. $3 E$ ), likely due to fura-2 binding to immobile molecules. Since fura-2's molecular weight was larger than glutamate's, glutamate washout should be faster and should occur before Train $_{1 \mathrm{~Hz}}$ application. Partial refilling from locally synthesized glutamate is highly unlikely, because synthesized glutamate should be quickly diluted and the mEPSC amplitude did not decrease (Fig. 1G).

\section{Large recycling pool}

Since the activity-dependent EPSC decrease is due to vesicle recycling without glutamate, the accumulated QEPSC as $\operatorname{Train}_{1 \mathrm{~Hz}}$ was repeated every $30 \mathrm{~s}$ without glutamate (इQEPSC; Fig. 4A) reflected glutamate-containing vesicles undergoing exocytosis for the first time. The $\Sigma$ QEPSC increased exponentially as Train $_{1 \mathrm{~Hz}}$ was repeated and approached a plateau level (Fig. 4A), reflecting depletion of glutamate-containing releasable vesicles, i.e., the recycling vesicle pool. The plateau level obtained from monoexponential fit (Fig. 4A) was 46 times the QEPSC induced by the first $20 \mathrm{~ms}$ depolarization during the first Train ${ }_{1 \mathrm{~Hz}}$, or 46 times the readily releasable pool (RRP) size because a $20 \mathrm{~ms}$ depolarization depletes the RRP (Wu and Borst, 1999; Xu and Wu, 2005). Since the vesicle number estimated from the EPSC or the $\Delta C_{\mathrm{m}}$ induced by a $20 \mathrm{~ms}$ depolarization matched approximately (Wölfel et al., 2007), we used $\Delta C_{\mathrm{m}}(464 \pm 28 \mathrm{fF}, n=8$; Fig. $1 A, B)$ induced by the first $20 \mathrm{~ms}$ depolarization during the first $\operatorname{Train}_{1 \mathrm{~Hz}}$ to estimate the RRP size. The RRP contained 6356 (464/0.073) vesicles, considering that a vesicle's membrane capacitance is $\sim 0.073 \mathrm{fF}$ (He et al., 2006). Accordingly, the recycling pool contained $\sim 292,000(46 \times 6356)$ vesicles, in the same order as an electron microscopic estimate ( $\sim 188,000$ vesicles) of the vesicle number in the calyx (de Lange et al., 2003). Our value is larger, perhaps because we selected large calyces for patch-clamping.

Assuming random mixing of recycled vesicles, we predicted the normalized QEPSC based on the measured recycling pool size (46 times the RRP size) and $\Delta C_{\mathrm{m}}$ induced by the first $\operatorname{Train}_{1 \mathrm{~Hz}}$ (6.0 times the RRP size; Fig. 4A). The predicted QEPSC (normal- 
A
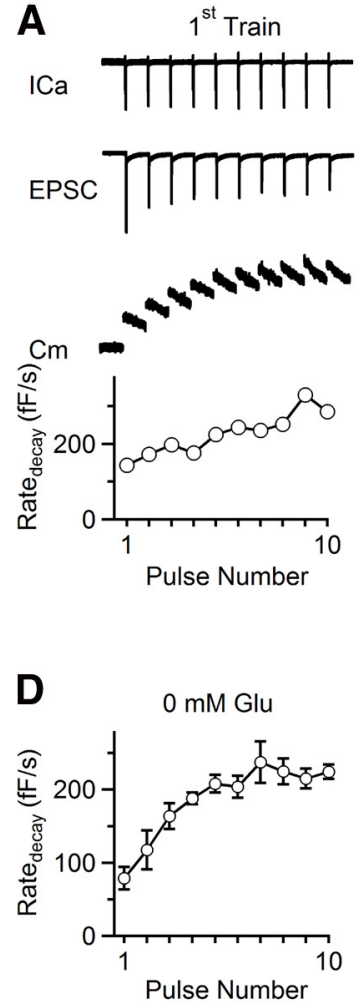
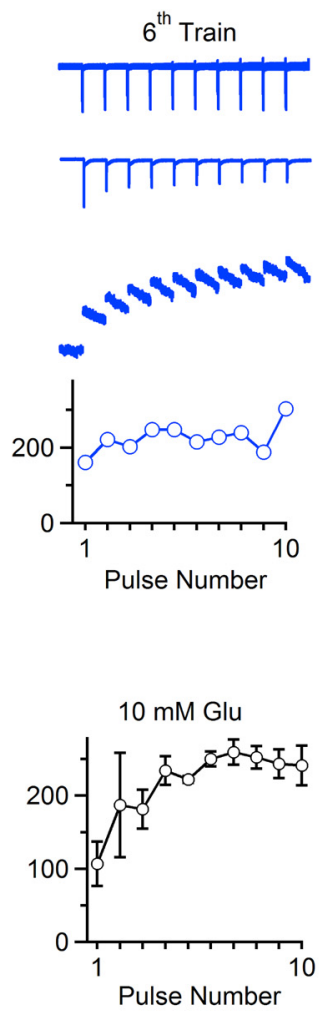
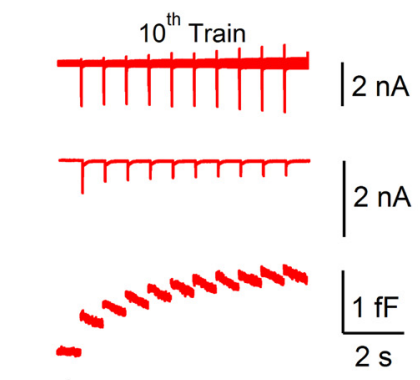

B
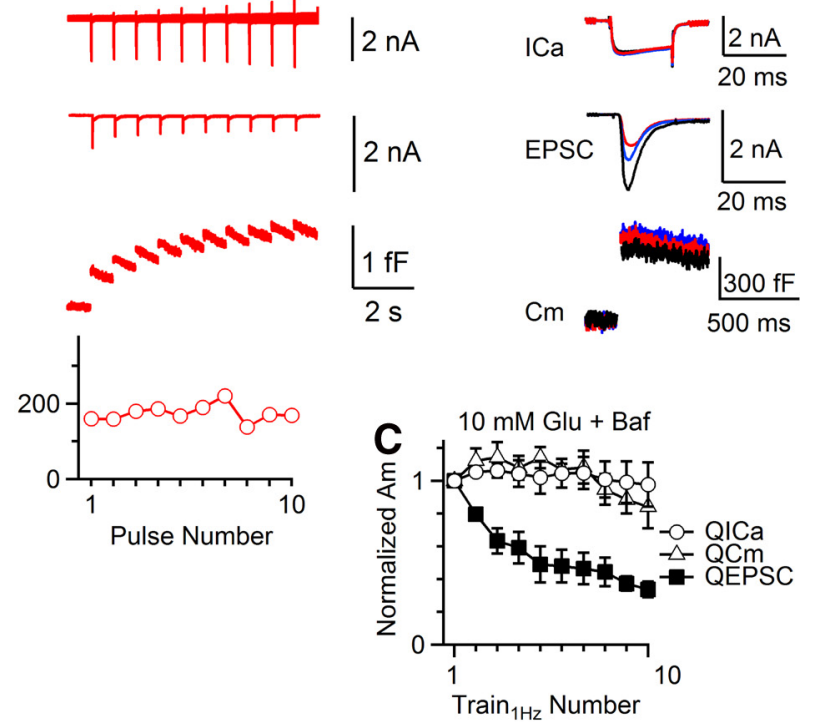

E

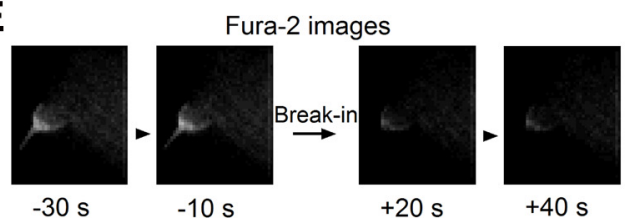

Figure 3. Block of glutamate uptake causes activity-dependent EPSC decrease. A-C, Same arrangements as in Fig. $2 A-C$ (10 mm glutamate), respectively, except that the bath contained bafilomycin A1 (Baf, $6 \mu \mathrm{m}, 20-30 \mathrm{~min}, n=4$ synapses). D. Capacitance rate of $C_{\mathrm{m}}$ decay (Rate decay) $_{\text {) }}$ after each $20 \mathrm{~ms}$ depolarization (from $\sim 300$ to $950 \mathrm{~ms}$ after depolarization) during the first Train $_{1 \mathrm{~Hz}}$ with $0 \mathrm{~mm}$ (left, $n=8$, data analyzed from Fig. 1) or $10 \mathrm{~mm}$ (right, $n=3$, data from Fig. 2) glutamate in the pipette. $\boldsymbol{E}$, Fura-2 images of a calyx before $(-30,-10 \mathrm{~s})$ and after $(+20,+40 \mathrm{~s}$ ) whole-cell break-in with a pipette containing no fura-2. Before taking these images, the calyx was preloaded with fura-2 using another whole-cell pipette containing $150 \mu \mathrm{m}$ fura-2, which was withdrawn $\sim 1$ min later and the calyx resealed.

ized to the RRP size $)$ was $6.0,5.2[(1-6.0 / 46) \times 6.0]$, etc... as Train $_{1 \mathrm{~Hz}}$ was repeated 1,2 , etc... times, which matched well with the measured QEPSC (Fig. 4A), confirming that the recycling pool is $\sim 46$ times the RRP size.

\section{Large recycling pool during action \\ potential-equivalent stimuli}

Our estimate of the recycling pool ( $\sim 292,000$ vesicles) was much larger than that labeled with FM dye ( $\sim 20,000$ vesicles) during action potential stimulation at $5 \mathrm{~Hz}$ (de Lange et al., 2003). To determine whether this discrepancy is due to a different stimulation protocol, we mimicked an action potential by a $1 \mathrm{~ms}$ depolarization to $+7 \mathrm{mV}$ (AP-e) (Sun et al., 2002; Xu and $\mathrm{Wu}, 2005$ ) and delivered the AP-e at $5 \mathrm{~Hz}$ for $180 \mathrm{~s}$ without glutamate (in pipette) or kynurenic acid (in bath; Fig. $4 B$ ). Since the mEPSC amplitude in the first and last $30 \mathrm{~s}$ of stimulation did not change significantly (Fig. 4C), we divided the accumulated EPSC by the mean mEPSC, yielding a total release of 33,000 \pm 5000 vesicles at the end of stimulation ( $n=8$; Fig. $4 D$ ). If there were only 20,000 vesicles in the recycling pool as FM dye labeling estimated (de Lange et al., 2003), the AP-e train should release them all and thus reduce the EPSC to 0 in the absence of glutamate. However, the EPSC evoked by an AP-e at 30-60 s before (3.30 $\pm 0.35 \mathrm{nA}, n=$ $8)$ and after $(3.29 \pm 0.44 \mathrm{nA}, n=8)$ the AP-e train was similar $(p>0.9$; Fig. $4 E$ ), suggesting that 33,000 vesicles represent only a small fraction of the large recycling pool. Consistently, a recycling pool containing 292,000 vesicles, as estimated during repetitive $\operatorname{Train}_{1 \mathrm{~Hz}}$ (Fig. $\left.4 A\right)$, predicted only a small $(\sim 11 \%)$ EPSC reduction when 33,000 vesicles are recycled without glutamate. In two synapses where we applied a $300 \mathrm{~s}$ AP-e train at $5 \mathrm{~Hz}$, we observed an $\sim 20-25 \%$ reduction of the EPSC at 30-60 s after the train (data not shown), further supporting a large recycling pool.

The large recycling pool was obtained when cytosolic glutamate was washed out. Would glutamate washout influence group III metabotropic glutamate receptor (mGluR) at calyces (Billups et al., 2005), and thus the recycling pool size? Two sets of evidence exclude this possibility. First, we repeated experiments in Figure $4 B-E$, but with $10 \mathrm{~mm}$ glutamate in the pipette and 300 or $0 \mu \mathrm{M}$ $(R, S)$-cyclopropyl-4-phosphonophenylglycine (CPPG), the group III mGluR antagonist, in the bath. In the presence (Fig. $4 F-H ; n=5$ ) or absence (Fig. $4 I-K ; n=5$ ) of CPPG, neither the mEPSC nor the EPSC was decreased after an AP-e train at $5 \mathrm{~Hz}$ for $180 \mathrm{~s}$, similar to those obtained without glutamate in the pipette (Fig. 4C-E). Second, the activity-dependent EPSC decrease was observed in the absence of glutamate or in the presence of glutamate and bafilomycin A1 (Figs. 1, 3A-C).

The large recycling pool was obtained at the whole-cell configuration. To determine whether presynaptic whole-cell dialysis influences our conclusion, we replaced presynaptic whole-cell stimulation with a bipolar extracellular electrode at the midline of the trapezoid body ( $\sim-15 \mathrm{~V}, 0.1 \mathrm{~ms}$, horizontal brainstem slice) to induce action potentials. In the presence $(n=4$; Fig. $4 L-N)$ or absence $(n=4)$ of bafilomycin A1 $(6 \mu \mathrm{M}$, bath), the mEPSC and the EPSC measured 30-60 s before and after a $5 \mathrm{~Hz}$ train for $180 \mathrm{~s}$ were similar $(p>0.6)$, suggesting that the recycling pool is too large to be depleted substantially. In three of these recorded synapses in the presence of bafilomycin A1, we resumed stimulation at $5 \mathrm{~Hz}$ for another $5 \mathrm{~min}$. The EPSC at 30-60 s after 


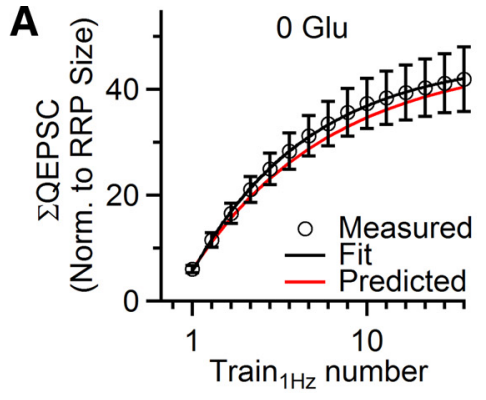

B
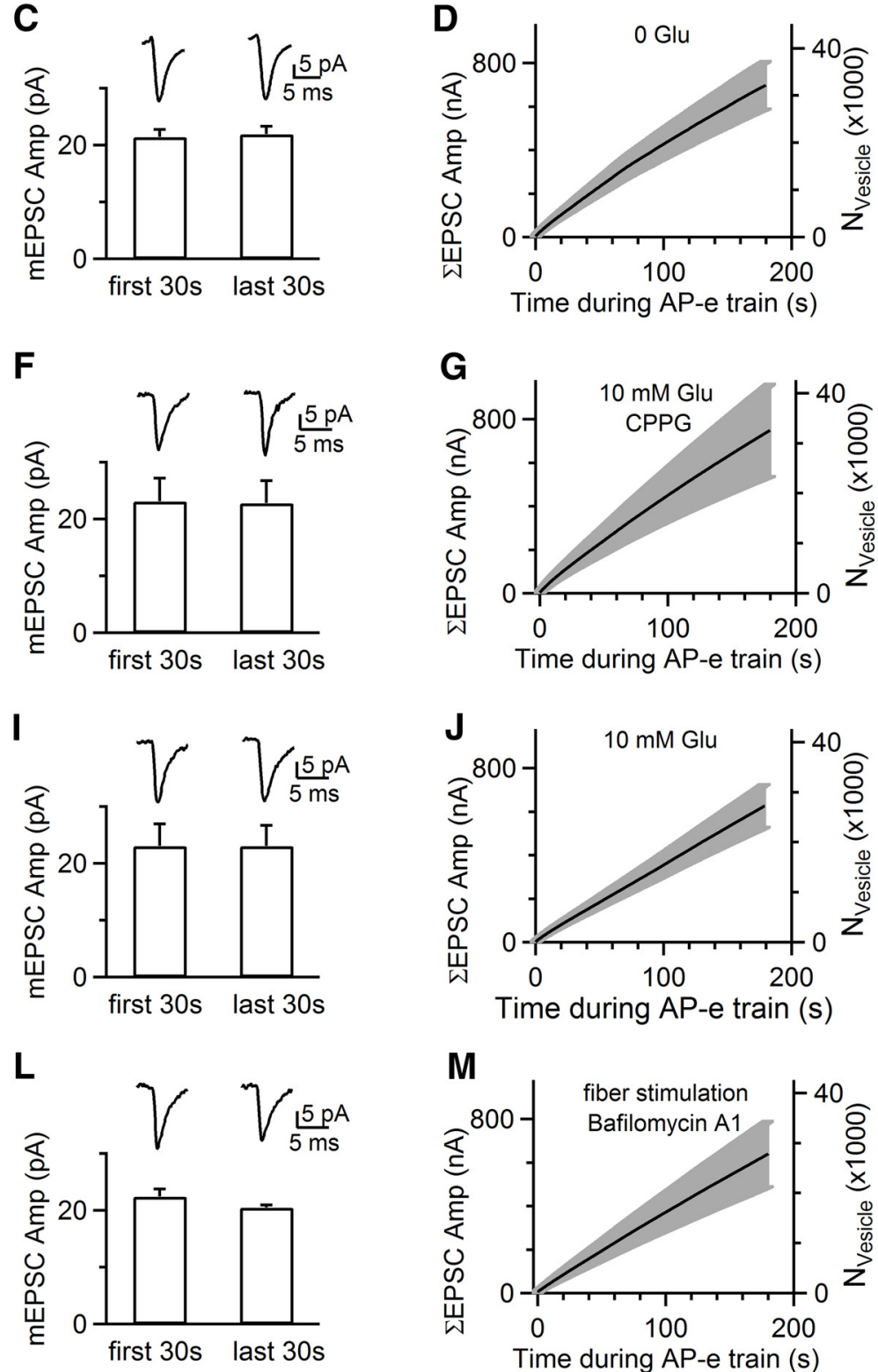
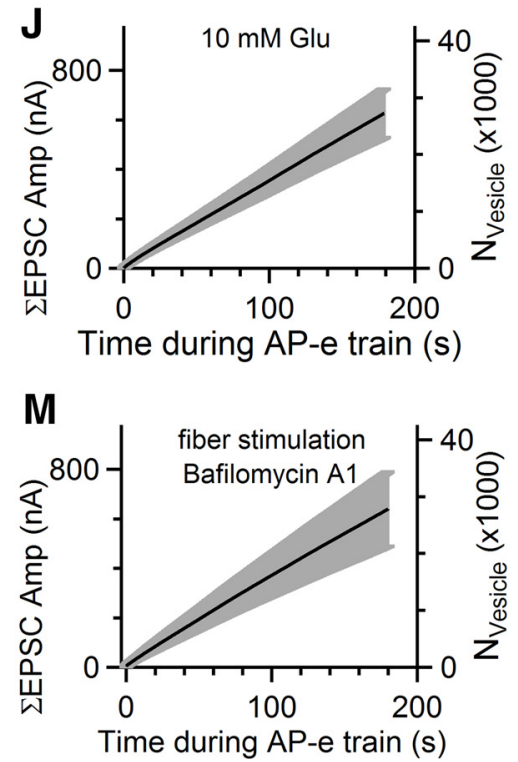

EPSC

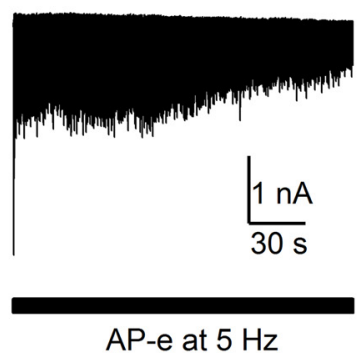

H
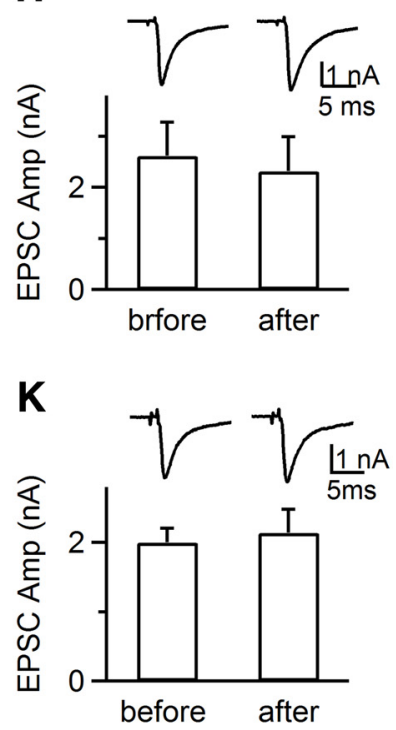

$\mathbf{N}$

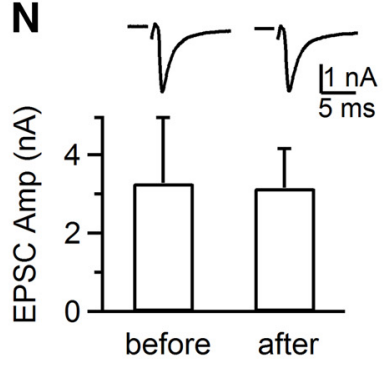

Figure 4. Large recycling pool. $A$, The accumulated QEPSC ( $\Sigma$ QEPSC, circles) induced by $\operatorname{Train}_{{ }_{1 \mathrm{~Hz}}}$ applied every $30 \mathrm{~s}$ is plotted versus the Train ${ }_{1 \mathrm{~Hz}}$ number in the absence of glutamate (analyzed from Fig. 10. 2 QEPSC is normalized to the QEPSC induced by the first $20 \mathrm{~ms}$ depolarization of the first $\operatorname{Train}_{1 \mathrm{~Hz}}$ i.e., the RRP size. Black curve is a monoexponential fit with a plateau value of 46 times the RRP size. The red curve is the predicted change assuming random mixture of recycling vesicles (see Results). B, Sampled EPSCs induced by a presynaptic AP-e train at $5 \mathrm{~Hz}$ for $180 \mathrm{~s}$ (bar) with no glutamate in the pipette (applies to $\boldsymbol{B}-\boldsymbol{E}$ ). . C, The mEPSC amplitude ( $n=8$ synapses) in the first and the last $30 \mathrm{~s}$ during the AP-e train at $5 \mathrm{~Hz}$ for $180 \mathrm{~s}$. Sampled mean mEPSCs at the same time period from a synapse shown in $\boldsymbol{B}$ are also plotted above the bar graph (left: averaged of $97 \mathrm{mEPSC}$; right: $93 \mathrm{mEPSCs})$. $\boldsymbol{D}$, The cumulative EPSC amplitude ( $\sum$ EPSC Amp) and the number of vesicles ( $\mathrm{N}_{\text {vesicle }}$ ) released by an AP-e train at $5 \mathrm{~Hz}$ ( $n=8$ synapses). Data are shown as the mean (solid curve) \pm SEM (gray). $E$, The amplitude of EPSCs (bottom) and sampled EPSCs (top, from one synapse) induced by an AP-e at $\sim 30 \mathrm{~s}$ before (left) and after (right) an AP-e train at $5 \mathrm{~Hz}$ for $180 \mathrm{~s}(n=8$ synapses). $\boldsymbol{F}-\boldsymbol{H}$, Same arrangements as in $\boldsymbol{C}-\boldsymbol{E}$, respectively, except that the pipette contained $10 \mathrm{~mm}$ glutamate and the bath contained $300 \mu \mathrm{M}$ CPPG ( $n=5$ synapses). mEPSC traces in $\boldsymbol{F}$ : left, averaged of $47 \mathrm{mEPSC}$; right, $56 \mathrm{mEPSCs}$. I-K, Same arrangements as in $\boldsymbol{C}-\boldsymbol{E}$, respectively, except that the pipette contained $10 \mathrm{~mm}$ glutamate (no CPPG in bath, $n=5$ synapses). $\mathrm{mEPSC}$ traces in $\boldsymbol{I}$ : left, averaged of $136 \mathrm{mEPSC}$; right, $58 \mathrm{mEPSC}$. L-N, Same arrangements as in C-E, respectively, except that whole-cell AP-e was replaced with an extracellular stimulation that induced axonal action potentials (see Results), and the bath contained $6 \mu \mathrm{m}$ bafilomycin A1 ( $n=4$, synapses). $\mathrm{mEPSC}$ traces in $M$ : left, $44 \mathrm{mEPSC}$; right, $51 \mathrm{mEPSCS}$. 
the train was reduced by $<30 \%$, consistent with the large recycling pool. These results were similar to those obtained without glutamate in the presynaptic pipette (Fig. $4 C-E$ ). Thus, wholecell presynaptic dialysis does not affect our finding of a large recycling pool.

\section{Discussion}

We found that at single calyces, the recycling pool contained $\sim 292,000$ vesicles or $\sim 46$ times the vesicles in the RRP during repetitive $\operatorname{Train}_{1 \mathrm{~Hz}}$ or AP-e train at $5 \mathrm{~Hz}$. This number was similar to the total vesicle number previously estimated by electron microscopy in the calyx (de Lange et al., 2003). Thus, the calyx maximizes its capacity in maintaining synaptic transmission by using essentially all vesicles for recycling.

The recycling pool we measured with EPSC recordings was much larger than the recycling pool ( $\sim 5-20 \%$ of total vesicles) morphologically labeled with FM dye at many synapses, including the calyx-type synapse (Harata et al., 2001b; Richards et al., 2003; de Lange et al., 2003; Rizzoli and Betz, 2004, 2005; Denker et al., 2011). The reason for this discrepancy is unclear. It has not been demonstrated that FM dye can label every endocytosed vesicle. For example, in a classical study, FM1-43 shows up in $86 \%$ of cisternae thought to reflect bulk endocytosis, whereas FM2-10 shows up in only $41 \%$ of cisternae (Richards et al., 2000). Based on the observation that prolonged higher-frequency or high potassium stimulation induced more FM dye-labeled vesicles, labeling of a small fraction of vesicles at low-frequency firing is suggested to reflect a small recycling pool. However, the possibility that FM dye uptake is different in different stimulation conditions has not been excluded. Different stimulation conditions induced different forms of endocytosis, including rapid, slow, bulk endocytosis and endocytosis overshoot (Richards et al., 2000; Clayton et al., 2007; Wu et al., 2009), which might take up FM dye differentially (Richards et al., 2000; Aravanis et al., 2003). A narrow fusion pore that closes rapidly, which has been suggested to take place in chromaffin cells (Chan and Smith, 2001; Chan and Smith, 2003), hippocampal synapses (Zhang et al., 2009), and calyces (Wu et al., 2005) during mild stimulation conditions, might prevent FM dye uptake into endocytosed vesicles. While this provides a potential explanation for a small recycling pool labeled with FM dye during low-frequency stimulation, whether this explanation holds remains to be tested. The present work developed a technique to count functional recycling vesicles at calyces, where only $\sim 5 \%$ vesicles are labeled by FM dye during firing at $5 \mathrm{~Hz}$ (de Lange et al., 2003). Our technique relies on washout of cytosolic glutamate while counting all released vesicles containing glutamate. We found that nearly all vesicles participate in recycling, which challenges the generally accepted small-recycling-pool principle.

Many studies of functional vesicle pools are in line with our findings. For example, when endocytosis is blocked, release of $>20,000$ vesicles (measured as $\sim 1.5 \mathrm{pF}$ in the $\Delta C_{\mathrm{m}}$ ) did not affect subsequent release (Wu et al., 2009). If the recycling pool contains only 20,000 vesicles (de Lange et al., 2003), subsequent release should be abolished. At calyces dialyzed with GTP- $\gamma S$ (and 0 mm glutamate) to block endocytosis, repetitive AP-e stimuli at $200 \mathrm{~Hz}$ releases approximately eight times the RRP, or $\sim 40,000-$ 50,000 vesicles, but only an $\sim 20 \%$ reduction in the EPSC measured 80 s later (Xu et al., 2008), consistent with a recycling pool of much $>50,000$ vesicles. A gradual block of release was observed when endocytosis was abolished by inhibition of dynamin at hippocampal synapses and Drosophila neuromuscular junctions (Koenig and Ikeda, 1989, 1996; Delgado et al., 2000;
Newton et al., 2006), which seems consistent with a large recycling pool. At physiological temperature, the recycling pool labeled by FM dye is approximately two times larger than at room temperature at hippocampal synapses (Micheva and Smith, 2005). A gradual block of EPSCs in the presence of bafilomycin A1 is observed at hippocampal synapses. By indirectly estimating the number of boutons involved in release, it is estimated that the recycling pool contained $\sim 80-130$ vesicles per bouton (Ikeda and Bekkers, 2009), which is higher than $\sim 31-64$ vesicles estimated with imaging methods (Harata et al., 2001a; Balaji and Ryan, 2007). While the difference could be potentially small (could be 80 vs 64 in the extreme), it might be due to several factors difficult to control at hippocampal synapses, such as the indirect estimate of the bouton number, and the lack of endocytosis measurements and an independent estimate of exocytosis other than the EPSC measurement. By controlling all these factors at calyces, including the calyx number, endocytosis, and measurements of exocytosis $\left(\Delta C_{\mathrm{m}}\right)$ other than the EPSC, we found that the functional recycling pool ( $\sim 292,000$ vesicles $)$ is $>10$-fold larger than the morphological estimate $(\sim 20,000)$ (de Lange et al., 2003). Together, it is likely that many synapses use all available vesicles for recycling to maximize their ability in maintaining synaptic transmission.

\section{References}

Aravanis AM, Pyle JL, Tsien RW (2003) Single synaptic vesicles fusing transiently and successively without loss of identity. Nature 423:643-647. CrossRef Medline

Balaji J, Ryan TA (2007) Single-vesicle imaging reveals that synaptic vesicle exocytosis and endocytosis are coupled by a single stochastic mode. Proc Natl Acad Sci U S A 104:20576-20581. CrossRef Medline

Billups B, Graham BP, Wong AY, Forsythe ID (2005) Unmasking group III metabotropic glutamate autoreceptor function at excitatory synapses in the rat CNS. J Physiol 565:885-896. CrossRef Medline

Chan SA, Smith C (2001) Physiological stimuli evoke two forms of endocytosis in bovine chromaffin cells. J Physiol 537:871-885. CrossRef Medline

Chan SA, Smith C (2003) Low frequency stimulation of mouse adrenal slices reveals a clathrin-independent, protein kinase C-mediated endocytic mechanism. J Physiol 553:707-717. CrossRef Medline

Clayton EL, Evans GJ, Cousin MA (2007) Activity-dependent control of bulk endocytosis by protein dephosphorylation in central nerve terminals. J Physiol 585:687-691. CrossRef Medline

de Lange RP, de Roos AD, Borst JG (2003) Two modes of vesicle recycling in the rat calyx of Held. J Neurosci 23:10164-10173. Medline

Delgado R, Maureira C, Oliva C, Kidokoro Y, Labarca P (2000) Size of vesicle pools, rates of mobilization, and recycling at neuromuscular synapses of a Drosophila mutant, shibire. Neuron 28:941-953. CrossRef Medline

Denker A, Bethani I, Kröhnert K, Körber C, Horstmann H, Wilhelm BG, Barysch SV, Kuner T, Neher E, Rizzoli SO (2011) A small pool of vesicles maintains synaptic activity in vivo. Proc Natl Acad Sci U S A 108:1717717182. CrossRef Medline

Harata N, Pyle JL, Aravanis AM, Mozhayeva M, Kavalali ET, Tsien RW (2001a) Limited numbers of recycling vesicles in small CNS nerve terminals: implications for neural signaling and vesicular cycling. Trends Neurosci 24:637-643. CrossRef Medline

Harata N, Ryan TA, Smith SJ, Buchanan J, Tsien RW (2001b) Visualizing recycling synaptic vesicles in hippocampal neurons by FM 1-43 photoconversion. Proc Natl Acad Sci U S A 98:12748-12753. CrossRef Medline

He L, Wu XS, Mohan R, Wu LG (2006) Two modes of fusion pore opening revealed by cell-attached recordings at a synapse. Nature 444:102-105. CrossRef Medline

Ikeda K, Bekkers JM (2009) Counting the number of releasable synaptic vesicles in a presynaptic terminal. Proc Natl Acad Sci U S A 106:29452950. CrossRef Medline

Ishikawa T, Sahara Y, Takahashi T (2002) A single packet of transmitter does not saturate postsynaptic glutamate receptors. Neuron 34:613-621. CrossRef Medline

Koenig JH, Ikeda K (1989) Disappearance and reformation of synaptic ves- 
icle membrane upon transmitter release observed under reversible blockage of membrane retrieval. J Neurosci 9:3844-3860. Medline

Koenig JH, Ikeda K (1996) Synaptic vesicles have two distinct recycling pathways. J Cell Biol 135:797-808. CrossRef Medline

Micheva KD, Smith SJ (2005) Strong effects of subphysiological temperature on the function and plasticity of mammalian presynaptic terminals. J Neurosci 25:7481-7488. CrossRef Medline

Newton AJ, Kirchhausen T, Murthy VN (2006) Inhibition of dynamin completely blocks compensatory synaptic vesicle endocytosis. Proc Natl Acad Sci U S A 103:17955-17960. CrossRef Medline

Richards DA, Guatimosim C, Betz WJ (2000) Two endocytic recycling routes selectively fill two vesicle pools in frog motor nerve terminals. Neuron 27:551-559. CrossRef Medline

Richards DA, Guatimosim C, Rizzoli SO, Betz WJ (2003) Synaptic vesicle pools at the frog neuromuscular junction. Neuron 39:529-541. CrossRef Medline

Rizzoli SO, Betz WJ (2004) The structural organization of the readily releasable pool of synaptic vesicles. Science 303:2037-2039. CrossRef Medline

Rizzoli SO, Betz WJ (2005) Synaptic vesicle pools. Nat Rev Neurosci 6:5769. CrossRef Medline

Scheuss V, Schneggenburger R, Neher E (2002) Separation of presynaptic and postsynaptic contributions to depression by covariance analysis of successive EPSCs at the calyx of Held synapse. J Neurosci 22:728-739. Medline

Sun JY, Wu LG (2001) Fast kinetics of exocytosis revealed by simultaneous measurements of presynaptic capacitance and postsynatpic currents at a central synapse. Neuron 30:171-182. CrossRef Medline

Sun JY, Wu XS, Wu LG (2002) Single and multiple vesicle fusion induce different rates of endocytosis at a central synapse. Nature 417:555-559. CrossRef Medline
Wölfel M, Lou X, Schneggenburger R (2007) A mechanism intrinsic to the vesicle fusion machinery determines fast and slow transmitter release at a large CNS synapse. J Neurosci 27:3198-3210. CrossRef Medline

Wong AY, Graham BP, Billups B, Forsythe ID (2003) Distinguishing between presynaptic and postsynaptic mechanisms of short-term depression during action potential trains. J Neurosci 23:4868-4877. Medline

Wu LG, Borst JG (1999) The reduced release probability of releasable vesicles during recovery from short-term synaptic depression. Neuron 23: 821-832. CrossRef Medline

Wu LG, Ryan TA, Lagnado L (2007) Modes of vesicle retrieval at ribbon synapses, calyx-type synapses, and small central synapses. J Neurosci 27: 11793-11802. CrossRef Medline

Wu W, Xu J, Wu XS, Wu LG (2005) Activity-dependent acceleration of endocytosis at a central synapse. J Neurosci 25:11676-11683. CrossRef Medline

Wu XS, McNeil BD, Xu J, Fan J, Xue L, Melicoff E, Adachi R, Bai L, Wu LG (2009) $\mathrm{Ca}(2+)$ and calmodulin initiate all forms of endocytosis during depolarization at a nerve terminal. Nat Neurosci 12:1003-1010. CrossRef Medline

Xu J, Wu LG (2005) The decrease in the presynaptic calcium current is a major cause of short-term depression at a calyx-type synapse. Neuron 46:633-645. CrossRef Medline

Xu J, McNeil B, Wu W, Nees D, Bai L, Wu LG (2008) GTP-independent rapid and slow endocytosis at a central synapse. Nat Neurosci 11:45-53. CrossRef Medline

Zhang Q, Li Y, Tsien RW (2009) The dynamic control of kiss-and-run and vesicular reuse probed with single nanoparticles. Science 323:1448-1453. CrossRef Medline 